\title{
OPTIMALISASI PENGGUNAAN MODEL PEMBELAJARAN INKUIRI UNTUK MENINGKATKAN PRESTASI BELAJAR PENDIDIKAN AGAMA HINDU DAN BUDI PEKERTI
}

\author{
Gusti Ayu Putu Sukarmi \\ SD Negeri 1 Sembung Gede \\ Email: gustiayuputusukarmini123@gmail.com
}

\begin{abstract}
ABSTRAK
Kemajuan mutu pendidikan utamanya peningkatan proses pembelajaran yang dilakukan guru di sekolah akan mampu diupayakan lewat sebuah penelitian tindakan. Oleh karenanya penulis mencoba melakukan penelitian ini demi adanya upaya perbaikan tersebut. Tujuan tersebut lebih jelas lagi dan lebih terfokus lagi adalah untuk meningkatkan prestasi belajar Pendidikan Agama Hindu dan Budi Pekerti siswa Kelas 1 semester I SD Negeri 1 Sembung Gede Tahun Pelajaran 2017/2018 setelah optimalisasi penggunaan model pembelajaran Inkuiri dalam pembelajaran. Peningkatan prestasi belajar tersebut datanya diperoleh lewat pemberian tes, setelah data diperoleh, selanjutnya dianalisis menggunakan analisis deskriptif. Perolehan data hasil penelitian ini, ternyata menggembirakan setelah cara pembelajaran yang konvensional dirubah menggunakan model Inkuiri. Kegiatan penelitian ini menghasilkan suatu peningkatan yang diharapkan yaitu meningkatnya perolehan data awal yang baru mencapai 69,79 dengan ketuntasan belajar $50 \%$ pada siklus I naik menjadi 72,44 dengan ketuntasan belajar $67 \%$, dan pada siklus II naik menjadi 82,72 dengan ketuntasan belajar 94\%. Hasil tersebut membuktikan keberhasilan penelitian ini sehingga peneliti berkesimpulan bahwa usaha maksimal penggunaan model pembelajaran Inkuiri dapat meningkatkan prestasi belajar Pendidikan Agama Hindu dan Budi Pekerti siswa kelas 1 semester I SD Negeri 1 Sembung Gede tahun pelajaran 2017/2018.
\end{abstract}

Kata kunci: Model Pembelajaran Inkuiri, Prestasi Belajar Pendidikan Agama Hindu dan Budi Pekerti.

\begin{abstract}
Progress in the quality of education primarily improves the learning process that teachers do in schools will be able to be pursued through an action research. Therefore the writer tries to do this research for the sake of these improvement efforts. The goal is clearer and more focused again to improve the learning achievement of Hindu Religious Education and Characteristics of students of Class 1 semester I of SD Negeri 1 Sembung Gede in the Academic Year of 2017/2018 after optimizing the use of Inquiry learning models in learning. Improved learning achievement is the data obtained through the provision of tests, after the data is obtained, then analyzed using descriptive analysis. The acquisition of data from this study, turned out to be encouraging after the conventional learning method was changed using the Inquiry model. This research activity resulted in an expected improvement, namely an increase in initial data acquisition which only reached 69.79 with 50\% learning completeness in the first cycle rose to 72.44 with $67 \%$ completeness learning, and in the second cycle rose to 82.72 with completeness learning $94 \%$. These results prove the success of this study so that researchers conclude that the maximum effort using the Inquiry learning model can improve the learning achievement of Hindu Religious Education and Characteristics of Grade 1 students of the first semester at SD Negeri 1 Sembung Gede in the academic year 2017/2018.
\end{abstract}

Keywords: Inquiry Learning Model, Learning Achievement in Hindu Religious Education and Human Ethic. 


\section{PENDAHULUAN}

Sampai sekarang pendidikan kita masih didominasi oleh pandangan bahwa pengetahuan sebagai perangkat fakta-fakta yang harus dihafal. Kelas masih berfokus pada guru sebagai sumber utama pengetahuan, kemudian ceramah menjadi pilihan utama strategi belajar. Untuk itu diperlukan sebuah strategi belajar baru yang lebih memberdayakan siswa. Sebuah strategi belajar yang tidak mengharuskan siswa menghafal fakta-fakta, tetapi sebuah strategi yang mendorong siswa mengkontruksikan dibenak mereka sendiri. Dalam proses belajar, anak belajar dari pengalaman sendiri, mengkonstruksi pengetahuan kemudian memberi makna pada pengetahuan itu. Melalui proses belajar yang mengalami sendiri, menemukan sendiri, secara berkelompok seperti bermain, maka anak menjadi senang, sehingga tumbuhlah motivasi untuk belajar, khususnya belajar Pendidikan Agama Hindu dan Budi Pekerti

Pembelajaran Pendidikan Agama Hindu dan Budi Pekerti di sekolah merupakan suatu usaha untuk mempersiapkan manusia untuk meyakini, memahami, dan mengamalkan agama Hindu itu sendiri. Pendidikan agama Hindu berfungsi menumbuhkan sikap dan perilaku manusia berdasarkan ajaran Agama Hindu dalam kehidupan sehari-hari serta pengetahuan tentang etika dengan tujuan untuk meningkatkan keyakinan dan penghayatan agar manusia dapat mengetahui mana yang baik dan mana yang tidak baik. Oleh karena itu pembelajaran Pendidikan Agama Hindu dan Budi Pekerti di sekolah sangat penting adanya. Sehingga dengan pengalaman yang semakin banyak siswa mampu mengetahui mana perbuatan baik dan buruk sehingga mutu pendidikan di Indonesia seimbang dengan pengetahuan yang lain.

Kenyataan umum yang dapat dijumpai di sekolah menunjukkan bahwa sebagian besar pembelajaran pendidikan Agama Hindu dan Budi Pekerti diberikan secara monoton dengan model pembelajaran yang berfokus pada pembelajaran konsep yang bersifat hafalan dan di dominasi guru tanpa banyak melihat kemungkinan penerapan metode lain yang sesuai dengan jenis materi, bahan dan alat yang tersedia. Akibatnya, siswa kurang berminat untuk mengikuti pelajaran yang diajarkan oleh guru tersebut dan tidak ada motivasi dari dalam dirinya untuk berusaha memahami apa yang diajarkan oleh guru, yang akan mempengaruhi hasil belajarnya. Hal ini sejalan dengan pendapat Somerset dan Suryanto dalam Angkowo \& Kosasih (2007:33) yang menyebutkan bahwa pembelajaran klasikal yang didominasi oleh guru mengakibatkan siswa kurang mencerna materi secara aktif dan konstruktif dimana siswa hanya mendengarkan penjelasan guru dan kurang aktif dalam proses pembelajaran, sehingga berpengaruh pada rendahnya hasil belajar siswa.

Semua harapan yang telah di sampaikan merupakan dasar yang patut diikuti dan dilaksanakan oleh guru dalam melaksanakan proses pembelajaran dikelas. Hal - hal tersebut merupakan kondisi yang diharapkan di pihak guru. Apabila guru betul-betul memahami hal tersebut dan mampu melakukannya dengan baik, tentu saja akan terpenuhi kondisi yang diharapkan dalam pembelajaran. Kenyataan yang ada dilapangan ternyata jauh dengan harapanharapan berbagai pihak.

Rendahnya prestasi belajar pendidikan Agama Hindu dan Budi Pekerti siswa kelas 1 semester I SD Negeri 1 Sembung Gede yang baru mencapai rata-rata 69,79 sedangkan KKM pada mata pelajaran Agama Hindu dan Budi Pekerti adalah 75. Hal ini menunjukkan bahwa peserta didik yang diteliti kemampuannya masih sangat rendah. Hanya kesenjangan tersebut membuat peneliti sebagai guru di sekolah ini harus segera mencari jalan keluar. Hal inilah yang membuat peneliti harus segera melakukan tindakan melalui Penelitian Tindakan Kelas ini.

Pembelajaran inkuiri adalah suatu pembelajaran yang menekankan kepada proses keterlibatan siswa secara penuh untuk dapat menemukan materi yang dipelajari dan menghubungkannya dengan situasi kehidupan nyata sehingga mendorong siswa untuk dapat menerapkannya dalam kehidupan mereka. Dengan membuat hubungan antara pengetahuan atau 
konsep yang telah dimiliki oleh siswa serta penerapannya dalam kehidupan sehari-hari, maka siswa akan mudah memahami materi yang diberikan.

\section{METODE PENELITIAN}

SD Negeri 1 Sembung Gede yang berlokasi di Jln.Maderi,Dsn Sembung Gede Kaja,Desa Sembung Gede,Kec.Kerambitan,Kab.Tabanan dipergunakan sebagai tempat diadakan penelitian tindakan kelas ini karena rendahnya prestasi belajar siswa. Situasi sekolah yang sejuk dan rindang karena banyak pohon tumbuh di halaman sekolah.

Rancangan penelitiannya menggunakan rancangan penelitian tindakan kelas yang dikemukakan Kemmis dan Robin McTaggart (dalam Agung, 1997:91) yang dapat dilihat pada gambar berikut.

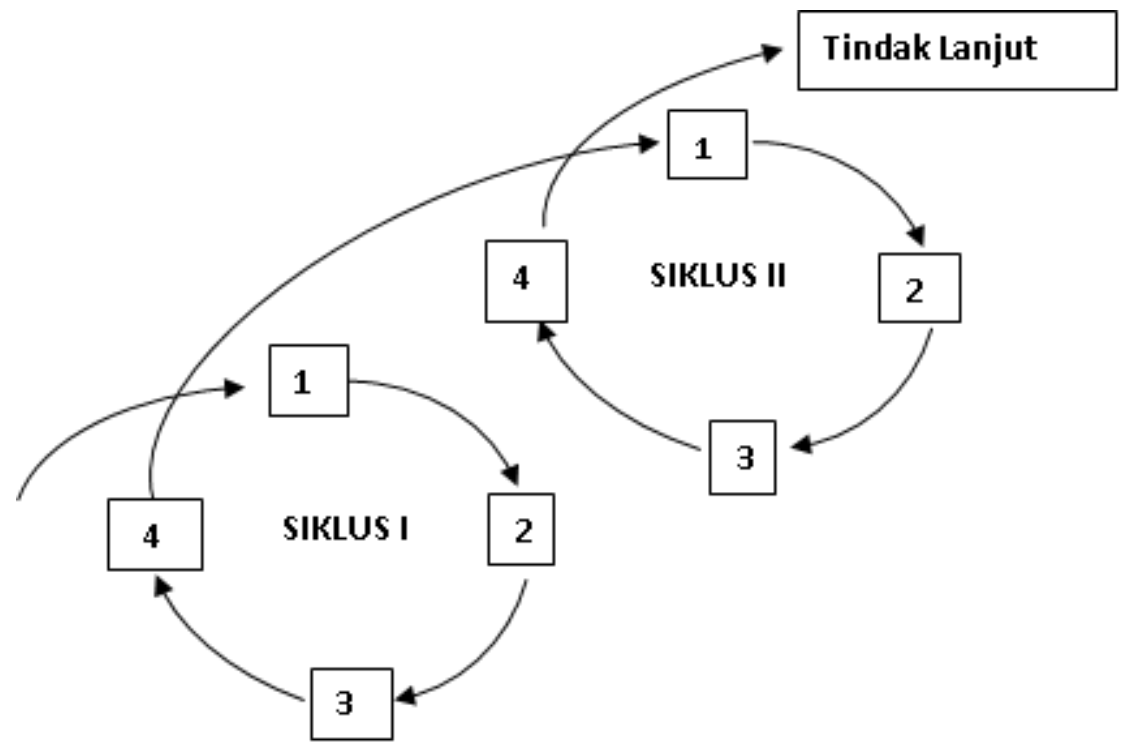

Gambar 1. Rancangan PTK dimodifikasi dari Model Kemmis dan Robin McTaggart (dalam Agung, 1997:91)

Subjek penelitian adalah siswa Kelas 1 yang belajar pada Semester I SD Negeri 1 Sembung Gede Tahun Pelajaran 2017/2018 yang berjumlah 18 orang. Objek penelitian Objek dalam penelitian ini adalah peningkatan prestasi belajar Pendidikan Agama Hindu dan Budi Pekerti siswa setelah diterapkannya model pembelajaran Inkuiri.

Metode pengumpulan data merupakan cara kerja dalam penelitian untuk memperoleh data atau keterangan-keterangan dalam kegiatan sesuai dengan kenyataan di lapangan. Metode yang digunakan untuk menganalisis data hasil penelitian ini adalah metode deskriptif untuk data kuantitatif. Untuk data kuantitatif dianalisis dengan mencari mean, median, modus, membuat interval kelas dan melakukan penyajian dalam bentuk tabel dan grafik.

Indikator keberhasilan penelitian tindakan kelas ini yang digunakan untuk menentukan keberhasilan pelaksanaan tindakan adalah KKM mata pelajaran Pendidikan Agama Hindu dan Budi Pekerti untuk kelas 1 adalah 75 pada semester I tahun pelajaran 2017/2018. Jika secara klasikal siswa sudah mencapai ketuntasan $85 \%$, memperoleh nilai tes akhir $\geq 75$ maka dikatakan sudah berhasil. 


\section{HASIL DAN PEMBAHASAN}

\section{Deskripsi Awal}

Pelaksanaan yang dilakukan dalam kegiatan awal diperoleh data yaitu, ada 9 orang siswa (50\%) dari 18 orang siswa di kelas 1 pada semester I tahun pelajaran 2017/2018 memperoleh nilai di atas KKM. Sedangkan 9 orang (50\%) mendapat nilai di bawah KKM.

\section{Deskripsi Siklus I}

Analisis yang dapat disampaikan pada Siklus I ini, penilaian terhadap kemampuan siswa menerpa ilmu pada mata pelajaran Pendidikan Agama Hindu dan Budi Pekerti adalah, dari 18 siswa yang diteliti, ada 12 orang siswa (67\%) memperoleh penilaian di atas dan sesuai KKM artinya mereka sudah mampu menerima dan mengaplikasikan materi yang diajarkan. Sedangkan 6 siswa (33\%) memperoleh nilai di bawah KKM

Hasil analisis ini menggambarkan bahwa prestasi belajar siswa masih jauh dari tuntutan indikator keberhasilan penelitian yang diusulkan, yaitu minimal mencapai nilai 75 sesuai KKM mata pelajaran Pendidikan Agama Hindu dan Budi Pekerti di sekolah ini. Adapun analisis kulitatifnya sebagai berikut.

a. Rata-rata (mean) dihitung dengan: $\frac{\text { Jumlah nilai }}{\text { Jumlah } \text { siswa }}=\frac{1304}{18}=72.44$

b. Median (titik tengahnya) dicari dengan mengurut data/nilai siswa dari yang terkecil sampai terbesar. Setelah diurut apabila jumlah data ganjil maka mediannya adalah data yang ditengah. Kalau jumlahnya genap maka dua data yang di tengah dijumlahkan dibagi 2 (dua). Untuk median yang diperoleh dari data siklus I dengan menggunakan cara tersebut adalah: 75

c. Modus (angka yang paling banyak/paling sering muncul) setelahdiasccending/diurut. Angka tersebut adalah: 75

d. Untuk persiapan penyajian dalam bentuk grafik maka hal-hal berikut dihitung terlebih dahulu.
1) Banyak kelas $(K)=1+3,3 \times \log (N)$

$$
\begin{aligned}
& =1+3,3 \times \log 18 \\
& =1+3,3 \times 1,24 \\
& =1+4,16=5
\end{aligned}
$$
2) Rentang kelas $(r)=$ skor maksimum - skor minimum$$
=85-50=35
$$

\begin{tabular}{|c|c|c|c|c|}
\hline No & Interval & Nilai Tengah & Frekuensi Absolut & Frekuensi Relatif \\
\hline 1 & $50-56$ & 53 & 1 & $6 \%$ \\
\hline 2 & $57-63$ & 60 & 4 & $22 \%$ \\
\hline 3 & $64-72$ & 67 & 1 & $6 \%$ \\
\hline 4 & $73-79$ & 76 & 8 & $44 \%$ \\
\hline 5 & $80-86$ & 83 & 4 & $22 \%$ \\
\hline \multicolumn{3}{|c|}{ TOTAL } & 18 & $100 \%$ \\
\hline
\end{tabular}
3) Panjang kelas interval (i) $=\frac{r}{K}=7$

Tabel 1. Data Kelas Interval Siklus I

\section{Deskripsi Siklus II}

Hasil yang diperoleh dengan pemberian tes prestasi belajar dapat dijelaskan: dari 33 orang siswa yang diteliti semuanya mendapat nilai rata-rata KKM dan melebihi KKM.. Interpretasi yang muncul dari data tersebut adalah bahwa mereka sudah sangat mampu melakukan apa yang disuruh. Analisis ini menunjukkan bahwa lebih dari setengah siswa sudah mampu meningkatkan prestasi belajarnya. Selanjutnya diberikan analisis kuantitatifnya menggunakan data yang diperoleh adalah dalam bentuk angka sebagai berikut: 
1. Rata-rata (mean) dihitung dengan: $\frac{\text { Jumlah nilai }}{\text { Jumlah siswa }}=\frac{1489}{18}=82,72$

2. Median (titik tengahnya) dicari dengan mengurut data/nilai siswa dari yang terkecil sampai terbesar. Setelah diurut apabila jumlah data ganjil maka mediannya adalah data yang ditengah. Kalau jumlahnya genap maka dua data yang di tengah dijumlahkan dibagi 2 (dua). Untuk median yang diperoleh dari data siklus I dengan menggunakan cara tersebut adalah: 80

3. Modus (angka yang paling banyak/paling seringmuncul) setelahdiasccending/diurut. Angka tersebut adalah: 80

4. Untuk persiapan penyajian dalam bentuk grafik maka hal-hal berikut dihitung terlebih dahulu.
1) Banyak kelas $(\mathrm{K})=1+3,3 \times \log (\mathrm{N})$$$
=1+3,3 \times \log 18
$$$$
=1+3,3 \times 1,24
$$$$
=1+4,16=5
$$
2) Rentang kelas $(r)=$ skor maksimum - skor minimum$$
=95-65=30
$$
3) Panjang kelas interval (i) $=\frac{r}{K}=3$

Tabel 2. Data Kelas Interval Siklus II

\begin{tabular}{|c|c|c|c|c|}
\hline No & Interval & Nilai Tengah & Frekuensi Absolut & Frekuensi Relatif \\
\hline 1 & $65-71$ & 7,5 & 1 & $6 \%$ \\
\hline 2 & $72-77$ & 74,5 & 2 & $11 \%$ \\
\hline 3 & $78-83$ & 80,5 & 6 & $33 \%$ \\
\hline 4 & 84-89 & 86,5 & 5 & $28 \%$ \\
\hline 5 & $90-95$ & 92,5 & 4 & $22 \%$ \\
\hline \multicolumn{3}{|c|}{ TOTAL } & 18 & $100 \%$ \\
\hline
\end{tabular}

Semua kegiatan yang telah dilakukan dari semua kegiatanpenelitian yang telah dilakukan disampaikan pada pembahasan ini.Untuk itu disajikan kebenaran hasil dan pelaksanaan yang telah dilakukan. Kegiatan awal menghasilkan diperoleh nilai rata-rata siswa sebesar 69,79. Hasil tersebut jauh di bawah KKM mata pelajaran Pendidikan Agama Hindu dan Budi Pekerti di SD Negeri 1 Sembung Geder hasil yang sangat rendah ini diakibatkan peneliti pada awalnya mengajar belum menggunakan model-model pembelajaran yang direkomendasi oleh ahli-ahli dunia. Peneliti lebih banyak berceramah, dan kegiatan siswa hanya mendengar dan mencatat saja. Setelah dicek perolehan nilai siswa, ada banyak siswa memperoleh nilai di bawah KKM. Hasil ini sangat mengejutkan sehungga peneliti sebagai guru di SD Negeri 1 Sembung Gede merasa terpanggil untuk memperbaiki proses pembelajaran. Hal tersebut membuat peneliti mencoba model Inkuiri

Dengan pelaksanaan pembelajaran telah diperbaiki pada siklus I ternyata hasil yang diperoleh sudah mencapai rata-rata 72,44. Namun rata-rata tersebut masih juga di bawah indikator keberhasilan penelitian yang diharapkan walaupun dalam pelaksanaannya peneliti telah berupaya secara maksimal seperti memotivasi siswa, memberi penekanan-penekanan, memberi arahanarahan dan lain sebagainya. Kelemaan yang ada justru pada belum mampunya peneliti memahami secara mendalam kebenaran dari teori model pembelajaran Pendidikan Agama Hindu dan Budi Pekerti yang digunakan dalam mengajar serta sintaks pembelajarannya.

Kelemahan-kelemahan yang masih tersisa pada pelaksanaan penelitian di siklus I, akhirnya peneliti proses pembelajaran diperbaiki agar diperoleh hasil yang lebih maksimal. Untuk itu pada siklus II diupayakan proses pembelajaran berjalan lebih baik dengan membuat perencanaan yang lebih matang, merumuskan tujuan, mengorganisasi materi lebih baik, mengupayakan agar materi berhubungan dengan kehidupan siswa sehari-hari. Setelah melakukan perencanaan yang matang, berlanjut dengan melakukan pembelajaran yang lebih maksimal dengan giat memberi 
motivasi, giat memberi arahan-arahan, menuntun agar siswa giat belajar, memberi contoh soal yang lebih banyak, mudah terlebih dahulu sebelum melanjutkan pada soal yang lebih sulit. Dengan soal-soal yang lebih mudah dapat dijawab maka mereka akan mendapat kepuasan awal yang akan berpengaruh terhadap keberhasilan selanjutnya.

Model Inkuiri diupayakan dalam pembelajaran mengikuti langkah-langkah secara teori yang benar. Pelaksanaan yang sudah maksimal pada siklus II ini mampu meningkatkan prestasi belajar peserta didik mencapai nilai rata-rata 82,72 dengan ketuntasan belajar $94 \%$. Ternyata nilai tersebut sudah melampaui indikator keberhasilan penelitian yang diusulkan. Dari hasil tersebut kelebihan-kelebihan pelaksanaan pada siklus II yang telah disampaikan di atas menjadi dasar validitas. Kelebihan-kelebihan tersebut adalah: model pembelajaran Inkuiri sudah dilaksanakan dengan benar sesuai teori yang ada, minat siswa sudah meningkat akibat peneliti giat memberi motivasi-motivasi, antosiasme belajar peserta didik meningkat akibat tugas-tugas yang selesai dikerjakan, kegiatan belajar mandiri peserta didik sudah mampu diupayakan dengan baik.

\section{KESIMPULAN}

\section{Simpulan}

Berdasarkan hasil penelitian diatas dapat dikatakan terjadi peningkatan prestasi belajar Pendidikan Agama Hindu dan Budi Pekerti dari kegiatan awal hingga Siklus 2. Sehingga dapat disimpulkan bahwa optimalisasi penggunaan model pembelajaran Inkuiri dapat meningkatkan prestasi belajar Pendidikan Agama Hindu dan Budi Pekerti siswa kelas 1 semester I SD Negeri 1 Sembung Gede Tabanan tahun pelajaran 2017/2018.

\section{Saran}

1) Usaha untuk membuat peningkatan mutu pendidikan memerlukan persiapan yang cukup matang, sehingga disarankan agar guru mampu menentukan atau memilih model yang benarbenar bisa diterapkan sehingga diperoleh hasil yang optimal; 2) Agar mampu meningkatkan prestasi belajar, maka guru hendaknya lebih sering melatih siswa dengan kegiatan penemuan, walau dalam taraf yang sederhana, agar para siswa menjadi berminat terhadap kegiatan yang dilakukan sehingga keaktifan belajar akan meningkat.

\section{DAFTAR PUSTAKA}

Arikunto, Suharsimi; Suhardjono; Supardi. 2006. Penelitian Tindakan Kelas. Jakarta: PT Bumi Aksara.

Arwati, Ni Made Sri. 2008. Hari Raya Nyepi. Denpasar: Tanpa Penerbit.

Jendra, Wayan. 2008. Tuhan Telah Mati, untuk Apa Sembahyang. Surabaya: Paramita.

Redana, Dewa Nyoman. 2015. "Makna Penggunaan Kober Ganesha saat Umat Hindu Melaksanakan Tawur Kesanga." Dalam Prosiding Seminar Local Genius dalam Perspektif Kebijakan Publik, Hukum, Manajemen, Pertanian, dan Pendidikan. Singaraja: P3M Unipas.

Suhardana, K.M. 2009. Roga Sanghara Bhumi: Jika Dunia Ini Mengalami Petaka dan Cara Mengatasinya. Surabaya: Paramita.

Sulendra, Wayan. 2011. "Ogoh-Ogoh dan Bhuta kala." Makalah yang Disampaikan pada Masyarakat Desa Banjarasem, Tanggal 15 April 2011.

Wiana, I Ketut. 2009. Makna Hari Raya Hindu. Surabaya: Paramita. 
Widana, I Gusti Ketut. 2009. "Ogoh-ogoh itu Bersifat Kultural.” Dalam Lima Cara Beryajnya: Bolehkah Nonton TV saat Nyepi. Denpasar: Pustaka Bali Post.

------. "Ogoh-ogoh Nyepi." Dalam Lima Cara Beryajnya: Bolehkah Nonton TV saat Nyepi. Denpasar: Pustaka Bali Post.

------. 2016. Ogoh-ogoh: Kapitalisasi Religi di Tataran Materi. Denpasar: Pustaka Bali Post.

Widnyani, Nyoman. 2012. Ogoh-ogoh: Fungsi dan Perannya di Masyarakat dalam Mewujudkan Generasi Emas Umat Hindu. Surabaya: Paramita. 